\title{
Walmart: Um Paraíso na Terra? Uma análise descritiva ao maior empregador privado dos Estados Unidos da América
}

Pedro Saraiva ${ }^{13}$

Resenha do livro:

REICH, Adam; BEARMAN, Peter. Working For Respect: Community and Conflict At

Walmart. Nova Iorque, Columbia University Press, 2018.

Será possível pensar em sociedades do Século XXI sem pensar no mundo do trabalho? Para alguns autores, a resposta seria "sim", mas essa seria uma resposta errada. Seria a mesma coisa que pensar o ser humano como um todo sem pensar de que este necessita de água para sobreviver. Voltando a pensar numa resposta possível para a questão que abre esta recensão, a resposta mais correta é um categórico "não". Não podemos pensar as sociedades do Século XXI sem pensar no mundo do trabalho e como essa esfera das nossas sociedades influenciam as outras esferas sociais. É pensando nessas influências que Adam Reich e Peter Bearman desenvolveram o projeto "Summer for Respect", no Verão de 2014, dando origem ao livro "Working for Respect: Community and Conflict at Walmart", publicado em 2018. Esses autores, de forma indireta, respondem à questão que abre esta recensão, apresentando várias questões relacionadas com o mundo do trabalho, estudando o caso do Walmart, nos Estados Unidos da América, e como esta empresa consegue interferir nas outras esferas da vida

13 Universidade de Coimbra (UC) - Coimbra - Portugal - pdgs@outlook.pt 
dos seus empregados. Ao longo de uma extensa introdução e de 7 capítulos, os autores fazem a exposição dos seus argumentos e que aqui são resumidos.

Na introdução a este livro, com o título "The Real, Real Walmart", Reich e Bearman apontam claramente a Walmart como o maior empregador privado dos EUA, com mais 1,4 milhões de empregados, espalhados por mais de 4000 lojas em todo o país (2018). Dando o exemplo de um jovem de 19 anos, mostram como a ideia de que o Walmart é um local onde se pode trabalhar para atingir o "sonho americano" é mentira, uma vez que os salários são baixos e não existe a possibilidade de progressão na carreira.

Comemorando os 50 anos do "Freedom Summer" (movimento social no qual voluntários brancos uniram-se para registar cidadãos americanos negros para poderem votar no Mississippi, em 1964), em 2014, os autores criam o projeto "Summer for Respect", no qual usaram 20 estudantes universitários ou recém-graduados, todos da área de Sociologia, no qual foram pagos para que, durante 9 semanas do verão desse ano, conduzissem histórias orais sobre os empregados do Walmart, em alguns pontos do país.

Com essa ideia presente, Reich e Bearman apresentam 3 objetivos centrais a atingir com o projeto: perceber melhor a relação entre os empregados e o Walmart; perceber a relação entre jovens universitários, de diferentes origens; perceber o papel dos acadêmicos na mudança social, ou seja, até que ponto é possível fazer uma "sociologia pública", conceito cunhado por Ruy Braga e Michael Burawoy (2008).

Depois desse projeto e já em 2016, falam de etnografias que realizaram em algumas lojas, e perceberam que apesar das más condições de trabalho, as pessoas sentem-se intimamente ligadas à empresa que os contratou, algo que veio ao encontro dos resultados que vão apresentar ao longo dos próximos capítulos. Os autores fazem uma apresentação breve e geral do projeto e das técnicas metodológicas que usaram em 2014. Apresentam, igualmente, os riscos e as tensões que poderiam vir a encontrar no decorrer do projeto, pelos participantes recrutados, para colocá-lo em prática.

No Capítulo 1, "Pathways", é feita ao leitor uma apresentação geral dos trabalhadores desta empresa. Algo que perceberam foi a heterogeneidade dos seus empregados: idades distintas, que vão desde mais jovens a pessoas quase para se aposentar, com vários passados distintos, com origens sociais diferentes e, como seria de se esperar, motivações distintas para trabalhar na Walmart, influenciando uma maior ou menor felicidade para trabalhar nesta mesma empresa. Reportando alguns dos casos aqui apresentados, as mulheres entrevistadas revelam que trabalhar no Walmart era uma forma de saírem de casa e 
ganhar a sua independência financeira em relação aos seus maridos. Destacam também as pessoas com mais de 50 anos, que, não querendo já se aposentar ou como forma de combater a solidão, preferem trabalhar mais alguns anos, trabalhando nesta empresa, ao mesmo tempo que combatem igualmente a solidão que sofrem. Em alguns dos casos apresentados, esta solução surge após a morte do cônjuge, combatendo a falta de dinheiro que deixou de estar disponível. Trabalhar no Walmart serve também para fugir de más situações (situações relacionadas com o uso de drogas, violência doméstica, situações de sem-abrigo etc.). Mesmo sabendo que os salários seriam relativamente baixos, sempre era melhor do que passar pelas situações relatadas anteriormente.

Trabalhar no Walmart não significava ter uma independência financeira total. Os salários baixos obrigam os trabalhadores a estarem dependentes dos subsídios estatais. O que não significa que os funcionários não estejam felizes de lá trabalhar, bem pelo contrário. Estando numa primeira fase dependentes dos subsídios estatais, trabalhar no Walmart permitia deixar de estar tão dependentes desses subsídios. Além disso, vende-se muito a ideia, entre os empregados, de que é possível fazer uma carreira na Walmart, sendo que esta depende sempre do seu empenho, mesmo que os salários sejam baixos. Esse é o desejo dos jovens que conseguem entrar nesta empresa e que pretendem ficar durante o máximo de tempo possível

No Capítulo 2, com o título “The Shop Floor", é percetível como os empregados, cada um nos seus departamentos, mostram orgulho no trabalho que faz, tirando mesmo fotografias daquilo que cada um atingiu. A par disto, a própria empresa tem um vasto sistema de incentivos monetários para premiar todos aqueles que se esforçam nas suas funções (Reich; Bearman, 2018). Esta é uma empresa na qual os empregados, com diferentes origens sociais, encontram um sentimento de comunidade e de pertença, desenvolvendo laços sociais fortes, com alguns casos de romance que acabam mesmo por surgir. Esse sentimento de pertença dá-se também pelo fato de que clientes e empregados conhecerem-se de outros círculos sociais, além da loja (andaram na mesma escola, vivem na mesma vizinhança, frequentam os mesmos locais públicos etc.). O sentimento é tal que os empregados, mesmo em dias de folga ou quando já não trabalham lá, são questionados pelos clientes sobre onde estão determinados produtos. Mesmo nestes dias, os próprios empregados acabam por ser sempre clientes da Walmart, devido aos preços baixos.

No entanto, os seus salários continuam baixos, mas comparando este indicador com outras empresas ao redor, com salários ainda mais baixos que os da Walmart, as pessoas continuam a preferir trabalhar nesta empresa. Além disso, 
sendo a competição por lugares na Walmart bastante grande, os empregados trabalham normalmente, mesmo quando não têm condições de saúde próprias para tal. Isso mostra a precariedade e o risco de desemprego a que estão sujeitas estas pessoas. Os salários são de tal maneira baixos que existem situações em que os empregados e os gerentes das lojas têm de contribuir para o fundo de apoio da Walmart, que apoia os empregados com maiores carências financeiras.

No capítulo imediato, "The Structure Of Control And Domination", os autores explicam como a Walmart faz todo o possível para criar sistemas que possam minimizar os custos e aumentar os seus lucros (maior eficiência e eficácia). No entanto, este sistema cria maior instabilidade nas lojas sobre quais os períodos do dia em que os produtos vão ter maior saída, criando incerteza relativamente aos estoques que devem estar em loja e no pessoal que deve trabalhar. Um sistema burocrático que cria bastante incerteza, sobretudo nos empregados. Devido a esta situação, os próprios trabalhadores devem ter a maior flexibilidade possível de horários, de forma a estarem disponíveis para trabalhar, e, consequentemente, mantendo os seus empregos. Acrescenta-se também que esta flexibilidade se verifica também durante as horas de trabalho, uma vez que o mesmo trabalhador poderá ter que realizar tarefas para vários gerentes ao mesmo tempo.

Além desta flexibilidade e pressão a que estão sujeitos, os empregados sofrem com os clientes, ou seja, seguindo a ideia de que os clientes têm sempre razão e, uma vez que os empregados estão cheios de tarefas, inevitavelmente existem falhas no atendimento ao cliente. Como consequência, os empregados sofrem represálias devido às queixas dos clientes à gerência. Tendo estas ideias presentes, os empregados preferem a dignidade a salários altos, uma ideia de comunidade em vez de mais horas de trabalho. É neste sentido que nasce o movimento "OUR Walmart".

O capítulo seguinte é exatamente sobre este movimento ("Making Contact"). A “Our Walmart" (OUR - Organization United for Respect) foi fundada em 2010 e surgiu como resposta às preocupações dos funcionários da Walmart e, segundo um estudo realizado por eles mesmos, a falta de respeito e de dignidade perante esses funcionários tornou-se o tema central e unificador desta organização.

No entanto, os trabalhadores desconfiam deste tipo de organização porque consideram que os sindicatos não representam os seus interesses e não têm força para se impor aos interesses da classe empregadora, não acreditando que seja possível trazer mudanças. E os primeiros anos de existência comprovam isso mesmo. Entre 2010 e 2015, mesmo com um grande número de pessoas a entrar 
no movimento, não foi suficiente para trazer mudanças na Walmart. São relatados casos de pessoas que, tendo se juntado ao movimento, acabariam mais tarde por ficar desempregadas. Houve mesmo uma perseguição da empresa a este movimento durante este período. No entanto, porque as pessoas se juntam ao movimento, mesmo sabendo do seu insucesso? Juntam-se porque aqui encontram um sentimento de pertença/comunidade, que por vezes não encontravam nas lojas onde estavam inseridos.

No capítulo 5, "Social Ties and Social Change", os autores fazem uma breve reflexão sobre o trabalho de campo realizado pelos participantes no projeto, apontando, sobretudo, as várias dificuldades encontradas no terreno (as dificuldades em conseguir falar com os empregados, foi a mais referida). Os participantes tiveram muitas dificuldades em falar com os empregados, tendo sido relatadas situações de perseguição de gerentes ou de polícia no interior das próprias lojas. Contudo, existiram igualmente situações em que os participantes sentiram um sentimento de pertença, nomeadamente entre os colegas da "OUR Wallmart", que em alguns casos fizeram um trabalho de integração destes mesmos participantes.

No capítulo 6, "Our Walmart On The Line", os autores focam-se um pouco mais neste movimento e nas suas ações contra a própria Walmart. Ficou comprovado que a empresa respondia sempre com uma mudança das suas políticas, o que silenciava todas as ações da "OUR Walmart". Além disso, uma vez que estas ações acabam por ser mais locais, devido ao carisma de líderes locais que surgiam em algumas lojas, era fácil encontrar os seus líderes e despedi-los, esmagando qualquer foco de revolta contra as condições de trabalho. Ora, pensando que os clientes têm sempre razão, uma estratégia de angariação de empregados para o movimento seria por meio de os clientes falarem do movimento. Algo que os participantes do projeto fizeram e, em alguns casos, deram mesmo resultado.

Focando a atenção do leitor nas comunidades online que esta organização criou para juntar os trabalhadores de todo o país, num espaço seguro onde poderiam conversar sem sentirem consequências, verificou-se claramente uma tendência. À medida em que iam entrando cada vez mais membros novos, os tópicos de conversa iam fugindo das questões relacionadas com o trabalho e focavam-se cada vez mais em tópicos da vida pessoal destas pessoas. Tal como no mundo offline, também neste mundo as pessoas queriam sentir-se membros de uma comunidade. Queriam sentir um apoio. Uma ideia de comunidade que foi criada nas lojas da Walmart, um pouco por todo o lado. Com esta ideia em mente, os autores defendem que se pode usar este sentimento de pertença que 
encontra online para tentar expandir as suas atividades nas lojas onde ainda não está presente e onde a sua presença é praticamente nula.

Usando este sentimento de comunidade para chegar aos empregados, a "OUR Walmart" criou a "WorkIt", que é uma aplicação no qual os empregados podem tirar dúvidas sobre as suas condições de trabalho, mas também podem interagir com outros colegas e tirarem dúvidas relativas à sua vida pessoal (saúde, educação etc.). É uma forma alternativa de os trabalhadores se sentirem interligados no mundo online. Para os autores, e caso seja bem trabalhada esta questão do mundo online, tem todas as possibilidades de ser bem-sucedido (Reich; Bearman, 2018).

Por fim, num capítulo que serve de conclusão, "Our Walmart", os autores fazem uma reflexão sobre os percursos dos participantes após a conclusão do projeto de Verão, realizado em 2014. Apesar de a maior parte destes ter seguido outros percursos profissionais diferentes da experiência profissional que tiveram nessa época, alguns destes participantes, já depois de graduados, continuaram a estar ligados ao movimento "OUR Walmart", ou ligados a outros movimentos de justiça social, desempenhando tarefas profissionais ligadas à sociologia pública, como os autores fazem referência na introdução. Com este projeto, os próprios autores corrigiram ideias erradas que tinham antes de começar o trabalho de campo, percebendo que o sentimento de comunidade, no caso particular da Walmart, é extramente importante para os empregados, não só para discutir questões laborais, mas sobretudo para discutir questões da vida pessoal. Os autores falam ainda sobre o percurso de alguns dos empregados cujas histórias são contadas ao longo do livro. Como concluem os autores, a maior parte deles, três anos depois da execução do projeto, já não trabalhava na Walmart. Todos estes foram substituídos por outros.

Como foi possível perceber anteriormente, este é um livro bastante denso em termos de informação que é apresentada ao leitor. Todavia, Adam Reich e Peter Bearman, de forma extensa, mas direta, de forma criteriosa, mas sem esconder nada do que pensam, apresentam uma descrição bastante eficaz do que é a Walmart, de como é a relação dos seus empregados (ou usando a expressão que é muito usado nos nossos dias, dos seus "colaboradores") entre si e com a empresa e as várias formas como trabalhar na Walmart pode mudar drasticamente a vida das pessoas, seja de uma maneira positiva, seja de uma maneira negativa.

Verificamos claramente que a Walmart, usando o seu vasto poder burocrático e econômico, consegue o máximo de lucro pelo menor custo possível. Verifica-se também como essas pessoas recebem salários baixos, e sabendo da 
competição entre as pessoas por lugares nesta empresa, contentam-se com estes salários. Pode-se mesmo ir buscar o conceito de "exército de reserva", que Karl Marx cunhou, no ido Século XIX, para mostrar que, atrás das pessoas empregadas, existiam um número interminável de pessoas para ocupar o seu lugar. Dessa forma, sujeitam-se às condições impostas pela entidade patronal. No entanto, movimentos de contestação emergem, como é o caso da "OUR Walmart", para tentar contrariar esta situação. Todavia, ainda não foi o suficiente para fazer frente à Walmart. Saindo deste exemplo e pensando no mundo do trabalho em geral, pode-se pensar que este tipo de situação acontece exatamente um pouco por todo o lado, com as entidades patronais a terem um grande controle sobre os seus empregados. Este é mais um exemplo dos vários já apresentados por outros autores sobre a atual exploração e precariedade da classe trabalhadora, em qualquer sociedade, mais ou menos desenvolvida. Mas este livro destaca-se de todos os livros anteriores que já foram publicados. E por quê?

Porque os autores exploram uma vertente que precisa de ser mais trabalhada: a transição para uma sociologia pública, virada para o público em geral. E, para isso, usam estudantes ou recém-graduados em sociologia. São estes jovens que estão saindo das universidades que devem incentivar cada vez mais o uso de uma sociologia pública e que não esteja confinada no espaço acadêmico. Ao participarem deste projeto, desenvolveram capacidades inerentes à sua área de formação, mas também aprenderam como a sociologia tem um papel importante na mudança social. Ao recrutar novos membros para a "OUR Walmart", perceberam que esta área não está confinada à academia, e mais do que estar fechada na academia, a sociologia deve ser usada para ajudar as pessoas e para promover a justiça e a mudança social.

Voltando à resposta inicial desta recensão crítica (Será possível pensar em sociedades do Século XXI sem pensar no mundo do trabalho?), os autores, com este livro, mostram claramente que não. Mas, reformulando a pergunta num novo sentido: "Será que é possível que a Sociologia possa pensar as influências do mundo do trabalho nas sociedades do Século XXI, ao mesmo tempo que age para uma mudança social efetiva?". Claramente que sim. Mais que identificar a forma de organização de uma empresa e sua influência na vida dos seus empregados, a sociologia tem o poder de contribuir para a mudança social, promovendo uma maior justiça social nas nossas sociedades. Mais que poder, a Sociologia deve realizar esta mudança e Adam Reich e Peter Bearman apontam para isso mesmo. 


\section{Referências:}

BRAGA, Ruy; BURAWOY, Michael. Por uma sociologia pública. São Paulo, Alameda, 2008.

REICH, Adam; BEARMAN, Peter. Working For Respect: Community and Conflict At Walmart. Nova Iorque, Columbia University Press, 2018.

Recebido em 03/12/2018

Aprovado em 10/05/2019

\section{Como citar esta resenha:}

SARAIVA, Pedro. Walmart: Um Paraíso na Terra? Uma análise descritiva ao maior empregador privado dos Estados Unidos da América. Contemporânea - Revista de Sociologia da UFSCar, v. 9, n. 1, jan.- jun. 2019, pp. 315-322. 